\title{
Homogeneous, heterogeneous or shrinkage estimators? Some empirical evidence from French regional gasoline consumption
}

\author{
Badi H. BALTAGI, Georges BRESSON $\dagger$ \\ James M. GRIFFIN* and Alain PIROTTE ${ }^{\ddagger}$
}

January 2002

\begin{abstract}
This paper contrasts the performance of heterogeneous and shrinkage estimators versus the more traditional homogeneous panel data estimators. The analysis utilizes a panel data set from 21 French regions over the period 1973-1998 and a dynamic demand specification to study the gasoline demand in France. Out-of-sample forecast performance as well as the plausibility of the various estimators are contrasted.
\end{abstract}

Keywords: Panel data; French gasoline demand; Error components; Heterogeneous estimators; Shrinkage estimators.

JEL classification: C23.

\footnotetext{
${ }^{*}$ Texas A\&M University.

${ }^{\dagger}$ ERMES, Université Paris II.

${ }^{\ddagger}$ ERMES, Université Paris II and GATE, Université Lyon II.

The authors wish to thank Jean-Loup MADRE, Research Director at INRETS, for his assistance with obtaining the data set.
} 


\section{Introduction}

With the increasing time dimension of panel data sets, some researchers including Robertson and Symons (1992), Pesaran and Smith (1995), and Pesaran, Smith and Im (1996) have questioned the poolability of the data across heterogeneous units. Instead, they argue in favor of heterogeneous estimates that can be combined to obtain homogeneous estimates if the need arises. Maddala, Srivastava and Li (1994) and Maddala et al. (1997) on the other hand argued in favor of shrinkage estimators that shrink the heterogeneous estimators towards the pooled homogeneous estimator. Previously, proponents of homogeneous panel estimators have acknowledged the potential heterogeneity among the cross-sectional units, but have assumed that the efficiency gains from pooling outweighed these costs. Clearly, in panel data sets with $T$ up to 10, traditional homogeneous panel estimators would appear the only viable alternative. But as $T$ reaches 25 or even 50 years of post-war annual data, the choice no longer seems clear-cut. Furthermore, asymptotic theory is unlikely to illuminate the choice. In this paper, we turn to prediction tests as well as plausibility of the estimates as a promising approach in empirical work for resolving this conundrum. We place the debate within the context of French gasoline demand with a panel data set from 21 regions of France over the period 1973-1998.

Several researchers have emphasized the gains from pooling (see Hsiao (1986) on the benefits of panels). In the context of a gasoline demand across 18 OECD countries over the period 1960-1990, Baltagi and Griffin (1997) argued for pooling the data as the best approach for obtaining reliable price and income elasticities. They also pointed out that pure cross-section studies cannot control for unobservable country effects, whereas pure time-series studies cannot control for unobservable oil shocks or behavioral changes occurring over time. But, even if one agrees that a pooled estimator is preferable to individual time-series or cross-section estimates, there remains the question of which pooled estimators yields the more plausible estimates.

More recently, the fundamental homogeneity assumption underlying pooled models has been called in question and alternative estimators have been proposed. Several authors ${ }^{1}$ argue in favor of heterogeneous estimates. Maddala, Srivastava and Li (1994) propose an iterative Bayesian shrinkage estimator based on individual estimates shrunk towards the pooled model estimates. On the other hand, Pesaran and Smith (1995) advocate abandoning the pooled approach altogether because of inherent parameter heterogeneity and relying upon the average response from individual regressions. Depending on

\footnotetext{
${ }^{1}$ See Robertson and Symons (1992), Maddala, Srivastava and Li (1994), Pesaran and Smith (1995), Maddala et al. (1997), Hsiao, Pesaran and Tahmiscioglu (1999) and Pesaran and Zhao (1999), among others.
} 
the extent of cross-sectional heterogeneity in parameters, researchers may prefer these heterogeneous estimators to the traditional pooled homogeneous parameter estimators. Despite the proliferation of these heterogeneous estimators, relatively little is known about their performance in applied work. Baltagi and Griffin (1997) and Baltagi, Griffin and Xiong (2000) contrast the performance of these estimators using panels for gasoline and cigarettes and out-of-sample forecast tests.

Following Baltagi and Griffin (1997), our objective here is to compare the performance of 10 homogeneous and 13 heterogeneous estimators applying them to gasoline consumption across 21 French regions over 1973-1998. Unlike previous work using international gasoline data, the focus here on 21 regions within France poses a very different type of data set for the heterogeneity versus homogeneity debate. Inter-regional differences in gasoline prices and income within France are likely to be much smaller than international price and income differences. Thus, the usual efficiency argument for pooling would seem to lose much of its force. At the same time, heterogeneities between the Paris region and rural sections of France would suggest that the heterogeneous estimators may outperform their homogeneous counterparts.

Our choice of regional French gasoline data also has some significant policy considerations. French transportation policy involves drawing up master plans to develop road and motorway improvements and construction. For these infrastructure plans, long-run traffic forecasts are updated every five years. Gasoline consumption serves as a key proxy for these traffic forecasts. In the 70's, and despite the first oil shock, there has been a steady growth of traffic which was fueled by the increasing number of cars. The mid-80's experienced a boom in the car market and car traffic, which was stimulated by low gasoline prices and by a quickly increasing share of diesel cars (using a $40 \%$ cheaper fuel in France). This traffic growth seemed to have slowed down in the 90's, but the growth rates are not homogeneous nationwide. Geographical factors are important in traffic analysis. For instance, for car use, the most dynamic segments are peri-urban and long distance traffic. So, we need to differentiate gasoline demand forecasts (or traffic forecasts). Differentiation speaks in favour of an administrative division (regions) since, at this executive level, planning and funding stakes stand. ${ }^{2}$ Furthermore, it is inside employment basins, e.g. inside regions, that we observe the greatest differences of car fleets and car uses. So, both from a methodological as well as a policy perspective, the study of gasoline demand is important since longrun price elasticity of gasoline remains an unresolved issue even if gasoline

\footnotetext{
${ }^{2}$ In France, $80 \%$ of fuel price at the pump can be attributed to regional and national taxes.
} 
demand has been studied extensively ${ }^{3}$.

Section 2 describes the model specification, the data set and the pooled and heterogeneous estimators to be compared. In section 3, we compare the plausibility of alternative estimates of price, income and car elasticities as well as the speed of adjustment path to the long-run equilibrium. In section 4 , we compare the forecast performance of these pooled and heterogeneous estimators using the model to provide 10-year forecasts of gasoline consumption. Section 5 summarizes the results and concludes.

\section{Model specification and estimators}

\subsection{Model specification}

Following Baltagi and Griffin (1997), we assume that the stock of energyusing equipment is fixed in the short-run and its utilization is supposed to be a function of normal economic influences. Over time, observed utilization is adopted to desired utilization through the familiar habit-persistence mechanism. So, the desired gasoline consumption per vehicle $(G A S / C A R)^{*}$ is posited to be a log-linear function of the real price of gasoline $\left(P_{M G} / P_{C P I}\right)$, real income per capita $(Y / N)$ and cars per capita $(C A R / N)$. The stock of cars is included to capture the likely effect of reduced vehicle utilization say, by a two-car family which does not necessarily drive twice the miles of a one-car family.

$$
\left(\frac{G A S}{C A R}\right)^{*}=\alpha\left(\frac{P_{M G}}{P_{C P I}}\right)^{\beta}\left(\frac{Y}{N}\right)^{\gamma}\left(\frac{C A R}{N}\right)^{\delta}
$$

Adjustment to desired consumption per vehicle is assumed to follow the firstorder partial adjustment process:

$$
\left(\frac{G A S}{C A R}\right)_{t} /\left(\frac{G A S}{C A R}\right)_{t-1}=\left(\left(\frac{G A S}{C A R}\right)_{t}^{*} /\left(\frac{G A S}{C A R}\right)_{t-1}\right)^{\theta}, 0<\theta<1
$$

Adding the region and time subscripts, the classical dynamic demand equation for gasoline per vehicle is:

$$
\begin{aligned}
\ln \left(\frac{G A S}{C A R}\right)_{i, t}= & \theta \ln \alpha+(1-\theta) \ln \left(\frac{G A S}{C A R}\right)_{i, t-1}+\theta \beta \ln \left(\frac{P_{M G}}{P_{C P I}}\right)_{i, t} \\
& +\theta \gamma \ln \left(\frac{Y}{N}\right)_{i, t}+\theta \delta \ln \left(\frac{C A R}{N}\right)_{i, t}+u_{i, t}
\end{aligned}
$$

\footnotetext{
${ }^{3}$ See Houthakker, Verleger and Sheehan (1974), Sweeney (1978), Griffin (1979), Bohi and Zimmerman (1984), Dahl and Sterner (1991) and Baltagi and Griffin (1997).
} 
We follow the usual convention of assuming that the disturbance term in equation (3) is specified as a one-way error component model:

$$
u_{i, t}=\square_{i}+\nu_{i, t}, i=1, \ldots, N, t=1, \ldots, T
$$

where $\square_{i}$ denotes a region-specific effect and $\nu_{i, t}$ is white noise. Under this formulation, the long-run price, income per capita and cars per capita responses are respectively: $(\theta \beta /(1-\theta)),(\theta \gamma /(1-\theta))$ and $(\theta \delta /(1-\theta))$ where $\theta$ is the adjustment coefficient and $(1-\theta)$, the speed of adjustment to the long-run equilibrium.

The data set consists of a panel of 21 French administrative regions covering the period 1973-1998. The variables are: the fuel consumption $(G A S)$; a petrol price index (integrating the growing part of diesel vehicles for which fuel is cheaper) $\left(P_{M G}\right)$ deflated by the consumer price index $\left(P_{C P I}\right)$; household income $(Y)$; regional French population $(N)$ and, the number of cars $(C A R)$ which is an important determinant of the long-run evolution of car traffic. $^{4}$ Table 1 summarizes the extent of data variation, both inter and intra-regionally for the key variables: gasoline consumption per car, price per capita, income and cars per capita. The price variation is predominantly within region while the income variation is a little over one-fourth between regions and a little less than three-fourths within regions. For cars per capita this variation is one-fifth between regions and four-fifths within regions. Given the preponderance of within variation in the independent variables this data set differs markedly from the Baltagi and Griffin (1997) comparison utilizing inter-country data. Under these conditions, one might expect heterogeneous estimators to perform more favorably than homogeneous estimators.

Table 1

Variabilities of the French regional data $(N=21, T=1973-1998)$

\begin{tabular}{lcccc}
\hline \hline pooled sample & $\ln \left(\frac{G A S}{C A R}\right)$ & $\ln \left(\frac{P_{M G}}{P_{C P I}}\right)$ & $\ln \left(\frac{Y}{N}\right)$ & $\ln \left(\frac{C A R}{N}\right)$ \\
\hline Total variability & 7.060 & 153.115 & 9.757 & 20.925 \\
& $(100 \%)$ & $(100 \%)$ & $(100 \%)$ & $(100 \%)$ \\
Between regional & $65.72 \%$ & $0.05 \%$ & $27.84 \%$ & $20.09 \%$ \\
Within regional & $34.28 \%$ & $99.95 \%$ & $72.16 \%$ & $79.91 \%$ \\
\hline \hline
\end{tabular}

\section{$2.2 \quad$ Homogeneous estimators}

We first consider three standard pooled estimators, assuming the exogeneity of all the regressors. These include OLS, which ignores the regional effects, the Within estimator, which allows for fixed regional effects, and GLS, which

\footnotetext{
${ }^{4}$ See the data appendix.
} 
assumes that regional effects are random. Since our model is dynamic, and even if all the explanatory variables are uncorrelated with the error components, the presence of serial correlation in the remainder error term or the presence of a random regional effect renders the lagged dependent variable correlated with the error term and leads to inconsistent least squares estimates.

Consequently, we also focus on pooled estimators employing two-stage least squares (2SLS) using as instruments the exogenous variables and their lagged values. In particular, we examine five alternative 2SLS pooled estimators. First, we consider a standard 2SLS estimator, making no attempt to improve efficiency by taking into account the random regional effect. This estimator is consistent only if the exogenous regressors are uncorrelated with the unobservable individual effects. Second, we report the Within 2SLS estimator, which transforms the data about region means and thereby eliminates any regional fixed effect. In addition, this instruments for the presence of the lagged dependent variable by using exogenous variables and their lagged values. The third estimator is first-difference 2SLS (FD2SLS) proposed by Anderson and Hsiao (1982) in which fixed or random regional effects are eliminated. However, first-differencing introduces autocorrelation in the remainder error term $\left(\nu_{i, t}-\nu_{i, t-1}\right)$ and thus inefficiency problems. Nevertheless, consistency is preserved by the use of predetermined variables as instruments. Keane and Runkle (1992), (hereafter denoted by KR) suggest a modification of the 2SLS estimator that allows for any arbitrary type of serial correlation in the $\nu_{i, t}$ 's. We refer to this estimator as 2SLS-KR. Still another variant would be to allow for any arbitrary form of serial correlation in the first differenced disturbances in the manner of Keane-Runkle. This is denoted as the FD2SLS-KR estimator. Although the FD2SLS and the FD2SLSKR estimates are quite similar, they generally differ appreciably from other 2SLS type estimators. Finally, following Arellano and Bond (1991), we used a GMM estimator on the first-differences specification (FDGMM) with instruments in levels. This incorporates more orthogonality conditions than is usually used by the Anderson and Hsiao (1982) estimator as well as a general robust variance-covariance matrix specification allowed by GMM. In addition, we employ a GMM procedure on a specification in levels with instruments in first-differences (GMM). In total, we compare 10 homogeneous estimators.

\subsection{Heterogeneous estimators}

Underlying the poolability of the data is the assumption of homogeneity of the parameters across regions. However, if this assumption is invalid the dynamic pooled model could be biased because of heterogeneity in the para- 
meters across regions. Pesaran and Smith (1995) proposed instead an average of the individual region regressions which yields a consistent estimate of the parameters as long as $N$ and $T$ tend to infinity. We therefore compute individual region regressions and the Pesaran and Smith average estimate to compare homogeneous as well as heterogeneous estimates of the regression coefficients. We also computed the Swamy (1970) random coefficient regression estimator which is a weighted average of the least squares estimates where the weights are inversely proportional to their variance-covariance matrices. Using a quite different approach, Maddala, Srivastava and Li (1994) claim that shrinkage Bayesian type estimators are superior to either the individual heterogeneous estimates or the homogeneous estimates, especially for prediction purposes. In this case, one "shrinks" the individual estimates towards the pooled estimate using weights depending on their corresponding variance-covariance matrices. From the individual maximum likelihood estimators, based on the normality assumption, several shrinkage estimators have been proposed in the literature including the empirical Bayes estimator, the iterative Bayes estimator and the iterative empirical Bayes estimator (see Maddala et al. (1997) for a description of these estimators). ${ }^{5}$ Maddala et al. (1997) estimated short- and long-run elasticities of residential natural gas and electricity demand using a panel of 49 states over the period 1970-1990. They found that individual time series regressions for each state gave wrong signs and were highly unstable. Although the pooled estimates gave the right signs and were more reasonable, Maddala et al. (1997) argued that these estimates are not valid because the hypothesis of homogeneity of the coefficients is rejected. They proposed the shrinkage estimators as a compromise between the unstable heterogeneous estimates and the untenable homogeneity assumption. Thus, depending on the extent of between regional heterogeneity in parameters, researchers may prefer either individual region regression estimates, the Pesaran and Smith average, or the shrinkage estimates to the traditional pooled homogeneous parameters estimates. In total, we compute 13 heterogeneous estimates including the ones described above and their instrumental variables counterpart.

\footnotetext{
${ }^{5}$ It is important to note that these shrinkage estimators were derived based on the strict exogeneity assumption of the regressors. Nevertheless, Maddala et al. (1997) argue that these estimators are still consistent but not efficient, when a lagged dependent variable is present among the regressors.
} 


\section{Comparison of parameter estimates}

\subsection{Results using homogeneous estimators}

Table 2 summarizes the homogeneous elasticity estimates utilizing the various estimators set forth in the previous section. In the first regression, OLS — which emphasizes between regional differences - finds non-significant income and price elasticities. Given the relatively small inter-regional variation in prices and income, this result should not be surprising. The 0.97 coefficient on lagged gasoline consumption is no doubt biased because it is correlated with the omitted specific effects. The Within estimator may be preferred in principle because it completely controls for region-specific effects and the possible correlation of these effects with the explanatory variables. Short-run price, income and car elasticities are very small $(-0.079,0.141$ and -0.240 respectively) but they are all significant. Moreover, the coefficient of lagged consumption (0.787) shows a strong habit persistence, so the long-run response is 4.7 times the short-run response. ${ }^{6}$ The long-run income elasticity is about $66 \%$ which confirms previous results of models which explicitly introduce the vehicle stock in the specification. ${ }^{7}$ Since the stock of cars enters both as a dependent and independent variable, the short-run transformed elasticity of gasoline consumption relatively to the car-fleet is $(1+\theta \delta)$, e.g. (0.76). The GLS estimates, which treat the $\square_{i}$ 's as random effects, lead to a 0.82 coefficient on lagged gasoline consumption. Both the short-run income and car elasticities are smaller than those found with the Within estimator. Nevertheless, these two estimators as a group of traditional estimators enjoy certain areas of conformity.

A number of alternative instrumental variable estimators 8 are designed to deal with the endogeneity problem of the lagged gasoline consumption variable. The simplest is 2SLS which differs from OLS only in that it assumes lagged consumption endogenous. Comparison of the OLS results with the 2SLS results, in Table 2, show a substantial fall in the lagged-gasoline consumption coefficient from 0.968 to 0.797 . Only the price elasticity $(-0.03$ in the short-run) is statistically significant. Generally, the 2SLS pooled estimates of $(1-\theta)$ are much lower than those models treating the lagged dependent variable as predetermined. The standard interpretation of such results is that the 2SLS estimators avoid biasing $(1-\theta)$ toward 1. Comparing the Within-2SLS estimates with the Within estimates, we note that the Within2SLS estimator finds a modest decrease of the lagged-gasoline consumption coefficient from 0.787 to 0.716 , and the remaining short-run elasticities also

\footnotetext{
${ }^{6}$ See, for instance, Bohi and Zimmerman (1984), Dahl and Sterner (1991) who found the long-run responses to be 3.3 times the short-run response.

${ }^{7}$ See Baltagi and Griffin (1997) who found a similar elasticity for 18 OECD countries.

${ }^{8}$ We use two lags on price, income and car per capita as additional instruments.
} 
do not differ widely. Since serial correlation of the $\nu_{i, t}$ 's may render our estimators asymptotically inefficient, we apply the 2SLS-KR that allows for any arbitrary type of serial correlation in the $\nu_{i, t}$ 's. First of all, there is almost no difference between the $2 \mathrm{SLS}$ and the $2 \mathrm{SLS}-\mathrm{KR}^{9}$ estimator except for the income and car elasticities, but these estimates are insignificant. Next, following Arellano and Bond (1991), we employ a GMM estimator. First, on a specification in levels with instruments in first-differences and later on a first-differences specification with instruments in levels (FDGMM). For the GMM and FDGMM estimators, we find quite similar results as those of the Within-2SLS estimator.

Another method of controlling for region effects, proposed by Anderson and Hsiao (1982), amounts to first differencing the data and then applying 2SLS using lagged values of predetermined variables as instruments, which is denoted by FD2SLS. Both FD2SLS and the FD2SLS-KR estimates are quite similar, but the elasticities estimates are much higher than their 2SLS counterparts. Short-run and long-run elasticities become significant with the FD2SLS-KR procedure. Overall, the pooled homogeneous estimates are reasonable, pretty stable across various estimators, have the right sign and are significant.

\subsection{Results using heterogeneous estimators}

Table 3 summarizes the results of the individual region regressions, the Pesaran and Smith average estimate, the Swamy random coefficients estimate, maximum likelihood and shrinkage type estimators. The individual OLS region regressions yield quite a wide range of variability with lagged-gasoline consumption coefficients across regions ranging from 0.10 to 0.90 , short-run elasticities of price (ranging from -0.25 to -0.06 ), income (ranging from -0.25 to 0.72 ) and car (ranging -1.06 to 0 ). The same variability is also exhibited by the individual 2SLS estimates. The range of individual 2SLS estimates suggests that the individual region estimates are highly unstable and unreliable. Indeed, the instability of parameter estimates from individual time series has been observed quite commonly in a variety of demand studies, providing a major argument for pooling. ${ }^{10}$ Pesaran and Smith's suggestion of using a simple average of the individual region estimates to obtain long-run elasticity estimates implies that the long-run elasticities for price are -0.352 (OLS) and -0.417 (2SLS), for income 0.957 (OLS) and 0.958 (2SLS), for car -1.341 (OLS) and -1.545 (2SLS). Likewise, Swamy's esti-

\footnotetext{
${ }^{9}$ Estimation is based upon 1978-1998 since it may be worth emphazing that if $T>N$, this procedure will fail since the variance-covariance matrix will be singular with rank $N$.

${ }^{10} \mathrm{See}$, for instance, Baltagi and Griffin (1997), for gasoline demand and Maddala et al. (1997) for residential demand for electricity and natural gas.
} 
mator gives long-run elasticities for price $(-0.387)$ for income $(0.889)$ and for car $(-1.383)$.

Maximum likelihood estimates under normality yield a narrower range of estimates on lagged-gasoline consumption coefficients ranging from 0.40 to 0.81. The short-run elasticities of price (ranging from -0.18 to -0.05 ), of income (ranging from 0.05 to 0.46 ) and of car (ranging from -0.71 to -0.10 ). The same conclusions occur for the empirical Bayes shrinkage estimator and for the iterative Bayes estimators (iterative shrinkage estimator and iterative empirical shrinkage estimator). Despite the fact that the shrinkage Bayes estimators seem to provide a smaller range of estimates than the individual regions estimates, there remains a much wider variability compared to the pooled homogeneous estimates reported in Table 2. For instance, Figure 1 shows that the long-run income per capita elasticities, estimated with individual OLS, exhibit a wide but unrealistic variability among the 21 French regions. On the other hand the Bayes estimators shrink the heterogeneous estimates towards a narrower range of variation. Values of long-run income elasticities are concentrated around unity, especially for the Iterative Empirical Bayes estimator. This is also true for long-run price elasticities, long-run car per capita elasticities and the same features occur for the instrumental variables shrinkage estimates. The shrinkage type estimators seems to provide a smaller more plausible range of estimates.

\section{Forecast properties}

In this section, we use the prediction-performance criteria to help us choose among alternative estimators. Given the large data set of 21 regions over 24 years, we estimate our model using a truncated data set (i.e., without the last ten years of data) and then apply each estimator to an out-of-sample forecast period. Table 4 gives a comparison of various predictors using the root mean square errors criterion (RMSE). Because of the ability of an estimator to characterize long-run as well as short-run responses is at issue, the average RMSE is calculated across the 21 regions at different forecast horizons. Specifically, each model was applied to each region, and out-of-sample forecasts for ten years were calculated. The relative forecast rankings are reported in Table 4 after one year, five years, and ten years. The overall average ranking for the full ten-year period is also reported. In comparing the relative performance of the various estimators, one can analyze these results from the following perspective: heterogeneous versus homogeneous, and one-year-ahead forecasts versus long-run forecasts. A comparison of heterogeneous versus homogeneous estimators reveals some interesting patterns. The individual OLS and individual 2SLS also perform poorly vis-a-vis the homogeneous estimators ranking 22 and 23 over the fifth and 10 year hori- 
zons. The Pesaran and Smith "average OLS", "average 2SLS" and Swamy's random coefficients estimator rank 13, 16 and 15, respectively for the 10 year average forecasts. The weak forecast performance of the Pesaran and Smith average and the Swamy estimators relative to the homogeneous estimators arise because of the parameter-instability problem of the individual region regressions. Similarly, the relatively weak performance of the shrinkage and Bayes type estimators (ranking from 11 to 21 for the 10 year average), can be attributed to their reliance upon the individual region parameter estimates. This ranking depends on the type of estimator, whether empirical Bayes, iterative Bayes or their IV version. Thus, what seemed as an advantage to the shrinkage estimator - that is, placing some weight on the individual region regressions - becomes a liability when parameter instability is severe.

The overall RMSE forecast rankings offer a strong endorsement for the homogeneous estimators due in large part to their parameter stability. Within2SLS ranks first, followed by Within, GLS, FDGMM, FD2SLS, OLS, FD2SLS$\mathrm{KR}$ for the 10 year average. In fact, the top ten estimators for the five-, tenand average ten-years forecasts are homogeneous parameters estimators. Endogeneity problems seem not to be severe since GLS, Within and Within2SLS give the lowest RMSE for the five, ten and overall ten-year average. See Figure 2 for a plot of the RMSE forecast, by French region, for the GLS estimator for the one, five and 10 year ahead forecasts.

\section{Summary and conclusions}

This paper confirms again the value of panel data sets and the emphasis given to pooled estimators using a French panel data set on gasoline demand across 21 regions over the period 1973-1998. Unlike previous evidence using panels for international gasoline demand across 18 OECD countries and cigarette demand across U.S. states, this French panel is very different in that inter-regional variation in price and income is small vis-a-vis the intra-regional variation. Particularly if the parameter heterogeneity among regions is important, they should be manifest in this type of panel. Our results show that when the data is used to estimate heterogeneous models across regions, individual estimates are highly variable, unstable and offer the worst out-of-sample forecasts. Despite the fact that shrinkage estimators outperform these individual estimates, they still have a wide range and are outperformed by simple homogeneous estimates in out-of-sample forecasts. Admittedly, this is another case study using French data, but it does add to the evidence that simplicity and parsimony in model estimation offer more plausible estimates and better forecasts. 


\section{Appendix: the data set}

Our data set consists of a pooled sample for 21 French regions covering the period 1973 to 1998. The data base has been built with the assistance of JeanLoup MADRE, Research Director at "INRETS" (Department of Transport Economics and Sociology, The French National Institute for Transport and Safety Research) in the framework of a workshop on traffic modelling.

- Consumption of gasoline $(G A S)$ has been computed from fuel sales (source: "Comité Professionel des Pétroles," Professional Committee of Petrols) using hypotheses on changes in fuel efficiency (miles per gallon separately for diesel and gasoline) and for the share of these fuels used by light vehicles (in France, diesel cars represent about $40 \%$ of total car traffic). These hypotheses are revised each year but are the same for each region. Consumption of gasoline is expressed in hundreds millions of vehicles kilometers travelled. So, we obtain an estimation of regional light traffic (private cars + light trucks). When this consumption is deflated by the number of cars, we observe the contrast between transit regions, like Bourgogne, where the "mean annual mileage per car" is high (about 17,000 km per year), and enclaved (Auvergne) or urban (Ile-de-France) regions where exchanges of interstate traffic tend to counterbalance each other.

- The price of motor gasoline $\left(P_{M G}\right)$, expressed in French francs per litre, integrates the growing part of diesel vehicles for which fuel is cheaper. This price has been liberalized in 1985 which induced different regional evolutions.

- Household income $(Y)$ is expressed in French francs (source: "INSEE", National Institute of Statistics and Economic Studies). INSEE has supplied regional series of gross disposable income until 1992. With fiscal statistics (income taxes), we have updated these series to 1998.

- Regional French population $(N)$, (source: "INSEE").

- Consumer price index $\left(P_{C P I}\right)$, base $100=1980$, (source: "INSEE").

- The stock of cars $(C A R)$ is computed from "la vignette", the annual tax on car ownership (source: "Ministère de l'Economie et des Finances," Treasury). During the period covered by our panel data set, it is rather correlated with economic growth, which may induce colinearity problems. But, as car ownership will approach saturation threshold, this correlation will decrease. Moreover, as car use has fluctuated in a rather narrow range (12, 000 to 16, $000 \mathrm{~km}$ per year since 1973, general mean 
being $14,527 \mathrm{kms}$ per year), our opinion is that traffic elasticity to carfleet should be 1, and that other factors should explain the evolution of the mean annual mileage per car. 


\section{References}

Anderson, T.W. and C. Hsiao, 1982, Formulation and estimation of dynamic models using panel data, Journal of Econometrics 18, 47-82.

Arellano, M. and S. Bond, 1991, Some tests of specification for panel data: Monte Carlo evidence and an application to employment equations, Review of Economic Studies 58, 277-297.

Baltagi, B.H. and J.M. Griffin, 1997, Pooled estimators v.s. their heterogeneous counterparts in the context of dynamic demand for gasoline, Journal of Econometrics 77, 303-327.

Baltagi, B.H., J.M. Griffin and W. Xiong, 2000, To pool or not to pool: Homogeneous versus heterogeneous estimators applied to cigarette demand, Review of Economics and Statistics 82, 117-126.

Bohi, D.R. and M. Zimmerman, 1984, An update on econometric studies of energy demand, Annual Review of Energy 9, 105-154.

Dahl, C. and T. Sterner, 1991, Analyzing gasoline demand elasticities: A survey, Energy Economics 11, 203-210.

Griffin, J.M., 1979, Energy conservation in the OECD: 1980 to 2000 (Ballinger, Cambridge).

Houthakker, H.S., P.K. Verleger and D. Sheehan, 1974, Dynamic demand for gasoline and residential electricity, American Journal of Agricultural Economics 56, 412-418.

Hsiao, C., 1986, Analysis of Panel Data (Cambridge University Press, Cambridge).

Hsiao, C., M.H. Pesaran and A.K. Tahmiscioglu, 1999, Bayes estimation of short run coefficients in dynamic panel data models, Chapter 11 in C. Hsiao, K. Lahiri, L.F. Lee and M.H. Pesaran, eds., Analysis of Panels and Limited Dependent Variable Models (Cambridge University Press, Cambridge), 268-296.

Keane, M.P. and D.E. Runkle, 1992, On the estimation of panel-data models with serial correlation when instruments are not strictly exogenous, Journal of Business and Economic Statistics 10, 1-9.

Maddala, G.S., V.K. Srivastava and H. Li, 1994, Shrinkage estimators for the estimation of short-run and long-run parameters from panel data models, working paper (Ohio State University, Ohio). 
Maddala, G.S., R.P. Trost, H. Li and F. Joutz, 1997, Estimation of shortrun and long-run elasticities of energy demand from panel data using shrinkage estimators, Journal of Business and Economic Statistics 15, 90-100.

Pesaran, M.H. and R. Smith, 1995, Estimating long-run relationships from dynamic heterogenous panels, Journal of Econometrics 68, 79-113.

Pesaran, M.H., R. Smith, and K.S. Im, 1996, Dynamic linear models for heterogenous panels, Chapter 8 in L. Mátyás and P. Sevestre, eds., The Econometrics of Panel Data: A Handbook of the Theory With Applications (Kluwer Academic Publishers, Dordrecht), 145-195.

Pesaran, M.H., and Z. Zhao, 1999, Bias reduction in estimating long-run relationships from dynamic heterogeneous panels, Chapter 12 in C. Hsiao, K. Lahiri, L.F. Lee and M.H. Pesaran, eds., Analysis of Panels and Limited Dependent Variable Models (Cambridge University Press, Cambridge), 297-322.

Robertson, D. and J. Symons, 1992, Some strange properties of panel data estimators, Journal of Applied Econometrics 7, 175-189.

Swamy, P.A.V.B., 1970, Efficient inference in a random coefficient regression model, Econometrica 38, 311-323.

Sweeney, 1978, The demand for gasoline in the United States: a vintage capital model, in Workshop on Energy and Supply and Demand, International Energy Agency, Paris, 240-277. 
Table 2 - Gasoline demand: homogeneous parameters estimates 1975-1998

\begin{tabular}{|c|c|c|c|c|c|c|c|}
\hline \multirow[b]{2}{*}{ Model type } & \multicolumn{4}{|c|}{ Short Run } & \multicolumn{3}{|c|}{ Long Run } \\
\hline & $\ln (\mathrm{GAS} / \mathrm{CAR})_{\mathrm{i}, \mathrm{t}-1}$ & $\ln \left(\mathrm{P}_{\mathrm{MG}} / \mathrm{P}_{\mathrm{CPI}}\right)_{\mathrm{i}, \mathrm{t}}$ & $\ln (\mathrm{Y} / \mathrm{N})_{\mathrm{i}, \mathrm{t}}$ & $\ln (\mathrm{CAR} / \mathrm{N})_{\mathrm{i}, \mathrm{t}}$ & $\ln \left(\mathrm{P}_{\mathrm{MG}} / \mathrm{P}_{\mathrm{CPI}}\right)_{\mathrm{i}, \mathrm{t}}$ & $\ln (\mathrm{Y} / \mathrm{N})_{\mathrm{i}, \mathrm{t}}$ & $\ln (\mathrm{CAR} / \mathrm{N})_{\mathrm{i},}$ \\
\hline \multicolumn{8}{|c|}{ Exogenous regressors } \\
\hline OLS & $\begin{array}{c}0.968 \\
(11.407)\end{array}$ & $\begin{array}{c}-0.023 \\
(-0.660)\end{array}$ & $\begin{array}{c}-0.025 \\
(-0.241)\end{array}$ & $\begin{array}{c}-0.007 \\
(-0.071)\end{array}$ & $\begin{array}{c}-0.724 \\
(-0.326)\end{array}$ & $\begin{array}{c}-0.799 \\
(-0.189)\end{array}$ & $\begin{array}{c}-0.225 \\
(-0.068)\end{array}$ \\
\hline Within & $\begin{array}{c}0.787 \\
(30.861)\end{array}$ & $\begin{array}{c}-0.079 \\
(-7.050)\end{array}$ & $\begin{array}{c}0.141 \\
(3.592)\end{array}$ & $\begin{array}{c}-0.240 \\
(-5.179)\end{array}$ & $\begin{array}{c}-0.375 \\
(-6.109)\end{array}$ & $\begin{array}{c}0.661 \\
(4.254)\end{array}$ & $\begin{array}{l}-1.126 \\
(-5.156)\end{array}$ \\
\hline GLS & $\begin{array}{c}0.822 \\
(35.089) \\
\end{array}$ & $\begin{array}{c}-0.064 \\
(-6.293) \\
\end{array}$ & $\begin{array}{c}0.074 \\
(2.185) \\
\end{array}$ & $\begin{array}{c}-0.157 \\
(-4.047) \\
\end{array}$ & $\begin{array}{c}-0.360 \\
(-5.212) \\
\end{array}$ & $\begin{array}{c}0.417 \\
(2.434) \\
\end{array}$ & $\begin{array}{c}-0.889 \\
(-3.305) \\
\end{array}$ \\
\hline \multicolumn{8}{|c|}{ Endogenous regressors } \\
\hline $2 \mathrm{SLS}$ & $\begin{array}{c}0.797 \\
(14.507)\end{array}$ & $\begin{array}{c}-0.030 \\
(-4.713)\end{array}$ & $\begin{array}{c}-0.026 \\
(-1.497)\end{array}$ & $\begin{array}{c}0.019 \\
(1.128)\end{array}$ & $\begin{array}{c}-0.151 \\
(-3.335)\end{array}$ & $\begin{array}{c}-0.128 \\
(-1.304)\end{array}$ & $\begin{array}{c}0.095 \\
(1.286)\end{array}$ \\
\hline Within-2SLS & $\begin{array}{c}0.716 \\
(9.232)\end{array}$ & $\begin{array}{c}-0.093 \\
(-6.421)\end{array}$ & $\begin{array}{c}0.200 \\
(2.274)\end{array}$ & $\begin{array}{c}-0.299 \\
(-4.091)\end{array}$ & $\begin{array}{c}-0.329 \\
(-4.671)\end{array}$ & $\begin{array}{c}0.705 \\
(4.421)\end{array}$ & $\begin{array}{c}-1.055 \\
(-5.486)\end{array}$ \\
\hline 2SLS-KR & $\begin{array}{c}0.738 \\
(36.858)\end{array}$ & $\begin{array}{c}-0.036 \\
(-3.620)\end{array}$ & $\begin{array}{c}-0.015 \\
(-0.819)\end{array}$ & $\begin{array}{c}0.038 \\
(0.965)\end{array}$ & $\begin{array}{c}-0.138 \\
(-3.386)\end{array}$ & $\begin{array}{c}-0.057 \\
(-0.783)\end{array}$ & $\begin{array}{c}0.146 \\
(0.968)\end{array}$ \\
\hline GMM & $\begin{array}{c}0.788 \\
(26.691)\end{array}$ & $\begin{array}{c}-0.082 \\
(-6.793)\end{array}$ & $\begin{array}{c}0.138 \\
(2.711)\end{array}$ & $\begin{array}{c}-0.247 \\
(-4.074)\end{array}$ & $\begin{array}{c}-0.390 \\
(-6.727)\end{array}$ & $\begin{array}{c}0.654 \\
(3.314)\end{array}$ & $\begin{array}{c}-1.170 \\
(-4.578)\end{array}$ \\
\hline FD2SLS & $\begin{array}{c}0.727 \\
(6.164)\end{array}$ & $\begin{array}{c}-0.194 \\
(-6.765)\end{array}$ & $\begin{array}{c}0.520 \\
(3.275)\end{array}$ & $\begin{array}{c}-0.767 \\
(-5.082)\end{array}$ & $\begin{array}{c}-0.711 \\
(-1.945)\end{array}$ & $\begin{array}{c}1.906 \\
(1.598)\end{array}$ & $\begin{array}{c}-2.813 \\
(-1.784)\end{array}$ \\
\hline FD2SLS-KR & $\begin{array}{c}0.721 \\
(32.530)\end{array}$ & $\begin{array}{c}-0.187 \\
(-15.178)\end{array}$ & $\begin{array}{c}0.509 \\
(24.661)\end{array}$ & $\begin{array}{c}-0.742 \\
(-17.130)\end{array}$ & $\begin{array}{c}-0.672 \\
(-33.844)\end{array}$ & $\begin{array}{c}1.828 \\
(10.493)\end{array}$ & $\begin{array}{c}-2.660 \\
(-21.221)\end{array}$ \\
\hline FDGMM & $\begin{array}{c}0.735 \\
(24.737)\end{array}$ & $\begin{array}{c}-0.091 \\
(-10.176)\end{array}$ & $\begin{array}{c}0.195 \\
(4.743)\end{array}$ & $\begin{array}{c}-0.280 \\
(-2.688)\end{array}$ & $\begin{array}{c}-0.344 \\
(-9.759)\end{array}$ & $\begin{array}{c}0.737 \\
(4.889)\end{array}$ & $\begin{array}{l}-1.059 \\
(-2.431)\end{array}$ \\
\hline
\end{tabular}

Numbers in parentheses denote $t$-statistics. 
Table 3 - Gasoline demand: heterogeneous parameters estimates 1975-1998

\begin{tabular}{|c|c|c|c|c|c|c|c|}
\hline \multirow[b]{2}{*}{ Model type } & \multicolumn{4}{|c|}{ Short Run } & \multicolumn{3}{|c|}{ Long Run } \\
\hline & $\ln (\mathrm{GAS} / \mathrm{CAR})_{\mathrm{i}, \mathrm{t}-1}$ & $\ln \left(\mathrm{P}_{\mathrm{MG}} / \mathrm{P}_{\mathrm{CPI}}\right)_{\mathrm{i}, \mathrm{t}}$ & $\ln (\mathrm{Y} / \mathrm{N})_{\mathrm{i}, \mathrm{t}}$ & $\ln (\mathrm{CAR} / \mathrm{N})_{\mathrm{i}, \mathrm{t}}$ & $\ln \left(\mathrm{P}_{\mathrm{MG}} / \mathrm{P}_{\mathrm{CPI}}\right)_{\mathrm{i}, \mathrm{t}}$ & $\ln (\mathrm{Y} / \mathrm{N})_{\mathrm{i}, \mathrm{t}}$ & $\ln (\mathrm{CAR} / \mathrm{N})_{\mathrm{i}, \mathrm{t}}$ \\
\hline \multicolumn{8}{|c|}{ Individual region OLS estimator } \\
\hline \multirow[t]{2}{*}{ Maximum } & 0.902 & -0.055 & 0.715 & -0.004 & -0.126 & 3.759 & -0.011 \\
\hline & $(9.468)$ & $(-0.643)$ & $(3.196)$ & $(-0.014)$ & $(-0.593)$ & $(1.210)$ & $(-0.014)$ \\
\hline \multirow[t]{2}{*}{ Median } & 0.580 & -0.129 & 0.460 & -0.597 & -0.330 & 1.078 & -1.358 \\
\hline & $(4.391)$ & $(-2.310)$ & $(2.514)$ & $(-2.554)$ & $(-1.518)$ & $(2.937)$ & $(-1.662)$ \\
\hline \multirow[t]{2}{*}{ Minimum } & 0.096 & -0.253 & -0.252 & -1.062 & -1.323 & -0.670 & -4.073 \\
\hline & $(0.685)$ & $(-5.646)$ & $(-1.176)$ & $(-4.622)$ & $(-0.950)$ & $(-1.084)$ & $(-3.040)$ \\
\hline \multirow[t]{2}{*}{ Average } & 0.590 & -0.144 & 0.392 & -0.549 & -0.352 & 0.957 & -1.341 \\
\hline & $(16.805)$ & $(-10.252)$ & $(7.507)$ & $(-9.228)$ & $(-7.703)$ & $(6.314)$ & $(-7.239)$ \\
\hline \multirow[t]{2}{*}{ Swamy } & 0.668 & -0.128 & 0.295 & -0.459 & -0.387 & 0.889 & -1.383 \\
\hline & $(14.381)$ & $(-7.488)$ & $(4.334)$ & $(-6.579)$ & $(-5.981)$ & $(4.628)$ & $(-5.739)$ \\
\hline \multicolumn{8}{|c|}{ Individual region maximum likelihood estimator } \\
\hline \multirow[t]{2}{*}{ Maximum } & 0.807 & -0.052 & 0.455 & -0.102 & -0.172 & 1.730 & -0.339 \\
\hline & $(13.017)$ & $(-3.784)$ & $(4.065)$ & $(-2.112)$ & $(-2.705)$ & $(2.302)$ & $(-1.649)$ \\
\hline \multirow[t]{2}{*}{ Median } & 0.656 & -0.131 & 0.333 & -0.500 & -0.380 & 1.000 & -1.400 \\
\hline & (7.888) & $(-5.478)$ & $(2.365)$ & $(-6.107)$ & $(-3.180)$ & $(2.178)$ & $(-3.465)$ \\
\hline \multirow[t]{2}{*}{ Minimum } & 0.400 & -0.184 & 0.045 & -0.708 & -0.721 & 0.149 & -2.774 \\
\hline & $(5.100)$ & $(-8.184)$ & $(0.600)$ & $(-6.081)$ & $(-4.580)$ & $(0.0617)$ & $(-4.778)$ \\
\hline \multicolumn{8}{|c|}{ Individual region empirical Bayes shrinkage estimator } \\
\hline \multirow[t]{2}{*}{ Maximum } & 0.828 & -0.055 & 0.539 & -0.106 & -0.153 & 2.255 & -0.297 \\
\hline & $(10.473)$ & $(-2.455)$ & $(3.550)$ & $(-1.188)$ & $(-2.167)$ & (1.679) & $(-1.110)$ \\
\hline \multirow[t]{2}{*}{ Median } & 0.641 & -0.132 & 0.375 & -0.556 & -0.342 & 1.014 & -1.351 \\
\hline & $(5.796)$ & $(-5.071)$ & $(2.702)$ & $(-3.386)$ & $(-5.024)$ & $(4.000)$ & $(-2.625)$ \\
\hline \multirow[t]{2}{*}{ Minimum } & 0.303 & -0.203 & -0.019 & -0.810 & -0.801 & -0.055 & -3.212 \\
\hline & $(2.898)$ & $(-5.680)$ & $(-0.135)$ & $(-5.032)$ & $(-3.335)$ & $(-0.134)$ & $(-3.703)$ \\
\hline \multicolumn{8}{|c|}{ Individual region iterative Bayes shrinkage estimator } \\
\hline \multirow[t]{2}{*}{ Maximum } & 0.812 & -0.121 & 0.415 & -0.470 & -0.277 & 2.214 & -1.222 \\
\hline & $(18.081)$ & $(-12.656)$ & $(10.459)$ & $(-37.427)$ & $(-9.478)$ & $(3.827)$ & $(-8.966)$ \\
\hline \multirow[t]{2}{*}{ Median } & 0.669 & -0.139 & 0.329 & -0.504 & -0.401 & 1.006 & -1.543 \\
\hline & $(11.573)$ & $(-10.917)$ & $(9.313)$ & $(-41.784)$ & $(-6.357)$ & $(4.865)$ & $(-6.074)$ \\
\hline \multirow[t]{2}{*}{ Minimum } & 0.529 & -0.160 & 0.242 & -0.528 & -0.726 & 0.514 & -2.504 \\
\hline & $(9.628)$ & $(-14.708)$ & $(6.086)$ & $(-38.832)$ & $(-4.378)$ & $(4.645)$ & $(-4.234)$ \\
\hline
\end{tabular}

Numbers in parentheses denote $t$-statistics. 
Table 3 (continued)

\begin{tabular}{|c|c|c|c|c|c|c|c|}
\hline \multirow[b]{2}{*}{ Model type } & \multicolumn{4}{|c|}{ Short Run } & \multicolumn{3}{|c|}{ Long Run } \\
\hline & $\ln (\mathrm{GAS} / \mathrm{CAR})_{\mathrm{i}, \mathrm{t}-1}$ & $\ln \left(\mathrm{P}_{\mathrm{MG}} / \mathrm{P}_{\mathrm{CPI}}\right)_{\mathrm{i}, \mathrm{t}}$ & $\ln (\mathrm{Y} / \mathrm{N})_{\mathrm{i}, \mathrm{t}}$ & $\operatorname{Ln}(\mathrm{CAR} / \mathrm{N})_{\mathrm{i}, \mathrm{t}}$ & $\ln \left(\mathrm{P}_{\mathrm{MG}} / \mathrm{P}_{\mathrm{CPI}}\right)_{\mathrm{i}, \mathrm{t}}$ & $\ln (\mathrm{Y} / \mathrm{N})_{\mathrm{i}, \mathrm{t}}$ & $\mathrm{Ln}(\mathrm{CAR} / \mathrm{N})_{\mathrm{i}, \mathrm{t}}$ \\
\hline \multicolumn{8}{|c|}{ Individual region iterative empirical Bayes shrinkage estimator } \\
\hline Maximum & $\begin{array}{c}0.738 \\
(26.842)\end{array}$ & $\begin{array}{c}-0.122 \\
(-16.957)\end{array}$ & $\begin{array}{c}0.382 \\
(18.851)\end{array}$ & $\begin{array}{c}-0.470 \\
(-39.246)\end{array}$ & $\begin{array}{c}-0.298 \\
(-12.789)\end{array}$ & $\begin{array}{c}1.461 \\
(6.803)\end{array}$ & $\begin{array}{c}-1.247 \\
(-16.191)\end{array}$ \\
\hline Median & $\begin{array}{c}0.662 \\
(21.617)\end{array}$ & $\begin{array}{c}-0.134 \\
(-17.306)\end{array}$ & $\begin{array}{c}0.330 \\
(14.891)\end{array}$ & $\begin{array}{c}-0.498 \\
(-40.334)\end{array}$ & $\begin{array}{c}-0.392 \\
(-10.268)\end{array}$ & $\begin{array}{c}0.976 \\
(6.776)\end{array}$ & $\begin{array}{c}-1.474 \\
(-12.786)\end{array}$ \\
\hline Minimum & $\begin{array}{c}0.590 \\
(20.254) \\
\end{array}$ & $\begin{array}{c}-0.143 \\
(-17.683) \\
\end{array}$ & $\begin{array}{c}0.276 \\
(13.052) \\
\end{array}$ & $\begin{array}{c}-0.513 \\
(-46.046) \\
\end{array}$ & $\begin{array}{c}-0.549 \\
(-9.018) \\
\end{array}$ & $\begin{array}{c}0.673 \\
(7.293) \\
\end{array}$ & $\begin{array}{c}-1.799 \\
(-10.408) \\
\end{array}$ \\
\hline \multicolumn{8}{|c|}{ Individual region 2 SLS estimator } \\
\hline Maximum & $\begin{array}{c}1.347 \\
(1.615)\end{array}$ & $\begin{array}{c}-0.020 \\
(-0.209)\end{array}$ & $\begin{array}{c}1.302 \\
(1.197)\end{array}$ & $\begin{array}{c}-0.101 \\
(-0.311)\end{array}$ & $\begin{array}{c}0.424 \\
(0.482)\end{array}$ & $\begin{array}{c}3.255 \\
(0.663)\end{array}$ & $\begin{array}{c}0.422 \\
(0.139)\end{array}$ \\
\hline Median & $\begin{array}{c}0.707 \\
(2.813)\end{array}$ & $\begin{array}{c}-0.135 \\
(-1.158)\end{array}$ & $\begin{array}{c}0.321 \\
(0.845)\end{array}$ & $\begin{array}{c}-0.457 \\
(-0.839)\end{array}$ & $\begin{array}{c}-0.384 \\
(-0.805)\end{array}$ & $\begin{array}{c}1.234 \\
(2.615)\end{array}$ & $\begin{array}{c}-1.582 \\
(-1.033)\end{array}$ \\
\hline Minimum & $\begin{array}{c}0.159 \\
(0.315)\end{array}$ & $\begin{array}{c}-0.285 \\
(-5.349)\end{array}$ & $\begin{array}{c}-0.450 \\
(-0.325)\end{array}$ & $\begin{array}{c}-1.318 \\
(-3.986)\end{array}$ & $\begin{array}{c}-2.706 \\
(-0.212)\end{array}$ & $\begin{array}{c}-3.142 \\
(-0.132)\end{array}$ & $\begin{array}{c}-6.593 \\
(-0.564)\end{array}$ \\
\hline Average & $\begin{array}{c}0.651 \\
(7.872)\end{array}$ & $\begin{array}{c}-0.145 \\
(-7.924)\end{array}$ & $\begin{array}{c}0.334 \\
(2.710)\end{array}$ & $\begin{array}{c}-0.538 \\
(-5.702)\end{array}$ & $\begin{array}{c}-0.417 \\
(-3.718)\end{array}$ & $\begin{array}{c}0.958 \\
(2.279)\end{array}$ & $\begin{array}{c}-1.545 \\
(-3.387)\end{array}$ \\
\hline \multicolumn{8}{|c|}{ Individual region IV maximum likelihood estimator } \\
\hline Maximum & $\begin{array}{c}1.322 \\
(134.921)\end{array}$ & $\begin{array}{c}-0.048 \\
(-2.320)\end{array}$ & $\begin{array}{c}0.581 \\
(8.159)\end{array}$ & $\begin{array}{c}-0.111 \\
(-1.664)\end{array}$ & $\begin{array}{c}0.451 \\
(27.616)\end{array}$ & $\begin{array}{c}2.304 \\
(5.123)\end{array}$ & $\begin{array}{c}0.516 \\
(9.525)\end{array}$ \\
\hline Median & $\begin{array}{c}0.710 \\
(15.438)\end{array}$ & $\begin{array}{c}-0.136 \\
(-8.664)\end{array}$ & $\begin{array}{c}0.294 \\
(4.252)\end{array}$ & $\begin{array}{c}-0.437 \\
(-9.576)\end{array}$ & $\begin{array}{c}-0.472 \\
(-7.344)\end{array}$ & $\begin{array}{c}1.112 \\
(4.732)\end{array}$ & $\begin{array}{c}-1.598 \\
(-7.521)\end{array}$ \\
\hline Minimum & $\begin{array}{c}0.323 \\
(5.681) \\
\end{array}$ & $\begin{array}{c}-0.262 \\
(-16.857) \\
\end{array}$ & $\begin{array}{c}-0.409 \\
(-25.520) \\
\end{array}$ & $\begin{array}{c}-1.157 \\
(-14.617) \\
\end{array}$ & $\begin{array}{c}-1.714 \\
(-2.494) \\
\end{array}$ & $\begin{array}{c}-1.114 \\
(-0.978) \\
\end{array}$ & $\begin{array}{c}-4.323 \\
(-2.907) \\
\end{array}$ \\
\hline \multicolumn{8}{|c|}{ Individual region IV empirical Bayes shrinkage estimator } \\
\hline Maximum & $\begin{array}{c}1.322 \\
(33.747)\end{array}$ & $\begin{array}{c}-0.044 \\
(-1.854)\end{array}$ & $\begin{array}{c}0.681 \\
(2.286)\end{array}$ & $\begin{array}{c}-0.116 \\
(-1.427)\end{array}$ & $\begin{array}{c}0.446 \\
(9.541)\end{array}$ & $\begin{array}{c}2.236 \\
(4.067)\end{array}$ & $\begin{array}{c}0.498 \\
(3.101)\end{array}$ \\
\hline Median & $\begin{array}{c}0.712 \\
(7.183)\end{array}$ & $\begin{array}{c}-0.137 \\
(-5.320)\end{array}$ & $\begin{array}{c}0.320 \\
(2.815)\end{array}$ & $\begin{array}{c}-0.445 \\
(-3.499)\end{array}$ & $\begin{array}{c}-0.456 \\
(-3.108)\end{array}$ & $\begin{array}{c}1.142 \\
(4.087)\end{array}$ & $\begin{array}{c}-1.611 \\
(-5.768)\end{array}$ \\
\hline Minimum & $\begin{array}{c}0.289 \\
(2.442) \\
\end{array}$ & $\begin{array}{c}-0.265 \\
(-14.007)\end{array}$ & $\begin{array}{c}-0.416 \\
(-6.400) \\
\end{array}$ & $\begin{array}{c}-1.171 \\
(-10.326)\end{array}$ & $\begin{array}{c}-1.770 \\
(-1.624) \\
\end{array}$ & $\begin{array}{c}-1.254 \\
(-0.645) \\
\end{array}$ & $\begin{array}{c}-4.291 \\
(-1.692) \\
\end{array}$ \\
\hline
\end{tabular}

Numbers in parentheses denote $t$-statistics. 
Table 3 (continued)

\begin{tabular}{|c|c|c|c|c|c|c|c|}
\hline \multirow[b]{2}{*}{ Model type } & \multicolumn{4}{|c|}{ Short Run } & \multicolumn{3}{|c|}{ Long Run } \\
\hline & $\ln \mathrm{GAS} / \mathrm{CAR})_{\mathrm{i}, \mathrm{t}-1}$ & $\ln \left(\mathrm{P}_{\mathrm{MG}} / \mathrm{P}_{\mathrm{CPI}}\right)_{\mathrm{i}, \mathrm{t}}$ & $\ln (\mathrm{Y} / \mathrm{N})_{\mathrm{i}, \mathrm{t}}$ & $\operatorname{Ln}(\mathrm{CAR} / \mathrm{N})_{\mathrm{i}, \mathrm{t}}$ & $\ln \left(\mathrm{P}_{\mathrm{MG}} / \mathrm{P}_{\mathrm{CPI}}\right)_{\mathrm{i}, \mathrm{t}}$ & $\ln (\mathrm{Y} / \mathrm{N})_{\mathrm{i}, \mathrm{t}}$ & $\operatorname{Ln}(\mathrm{CAR} / \mathrm{N})_{\mathrm{i}, \mathrm{t}}$ \\
\hline \multicolumn{8}{|c|}{ Individual region IV iterative Bayes shrinkage estimator } \\
\hline Maximum & $\begin{array}{c}1.311 \\
(39.439)\end{array}$ & $\begin{array}{c}-0.036 \\
(-1.688)\end{array}$ & $\begin{array}{c}0.630 \\
(6.154)\end{array}$ & $\begin{array}{c}-0.099 \\
(-1.378)\end{array}$ & $\begin{array}{c}0.442 \\
(11.272)\end{array}$ & $\begin{array}{c}2.443 \\
(2.310)\end{array}$ & $\begin{array}{c}0.482 \\
(3.581)\end{array}$ \\
\hline Median & $\begin{array}{c}0.719 \\
(16.320)\end{array}$ & $\begin{array}{l}-0.134 \\
(-6.093)\end{array}$ & $\begin{array}{c}0.295 \\
(2.830)\end{array}$ & $\begin{array}{c}-0.431 \\
(-3.930)\end{array}$ & $\begin{array}{c}-0.468 \\
(-1.678)\end{array}$ & $\begin{array}{c}1.169 \\
(4.956)\end{array}$ & $\begin{array}{c}-1.427 \\
(-2.669)\end{array}$ \\
\hline Minimum & $\begin{array}{c}0.276 \\
(2.642) \\
\end{array}$ & $\begin{array}{c}-0.271 \\
(-16.168) \\
\end{array}$ & $\begin{array}{c}-0.423 \\
(-7.574) \\
\end{array}$ & $\begin{array}{c}-1.218 \\
(-11.959) \\
\end{array}$ & $\begin{array}{c}-1.858 \\
(-1.671) \\
\end{array}$ & $\begin{array}{c}-1.397 \\
(-0.699)\end{array}$ & $\begin{array}{c}-4.850 \\
(-1.959) \\
\end{array}$ \\
\hline \multicolumn{8}{|c|}{ Individual region IV iterative empirical Bayes shrinkage estimator } \\
\hline Maximum & $\begin{array}{c}1.311 \\
(34.055)\end{array}$ & $\begin{array}{c}-0.053 \\
(-2.171)\end{array}$ & $\begin{array}{c}0.514 \\
(4.533)\end{array}$ & $\begin{array}{c}-0.104 \\
(-1.210)\end{array}$ & $\begin{array}{c}0.466 \\
(9.180)\end{array}$ & $\begin{array}{c}2.193 \\
(3.657)\end{array}$ & $\begin{array}{c}0.562 \\
(3.249)\end{array}$ \\
\hline Median & $\begin{array}{c}0.749 \\
(16.071)\end{array}$ & $\begin{array}{c}-0.116 \\
(-3.787)\end{array}$ & $\begin{array}{c}0.229 \\
(2.697)\end{array}$ & $\begin{array}{c}-0.393 \\
(-11.645)\end{array}$ & $\begin{array}{c}-0.503 \\
(-4.504)\end{array}$ & $\begin{array}{c}0.938 \\
(7.556)\end{array}$ & $\begin{array}{l}-1.659 \\
(-5.451)\end{array}$ \\
\hline Minimum & $\begin{array}{c}0.438 \\
(4.425)\end{array}$ & $\begin{array}{c}-0.252 \\
(-13.039)\end{array}$ & $\begin{array}{c}-0.391 \\
(-6.174)\end{array}$ & $\begin{array}{l}-1.088 \\
(-9.510)\end{array}$ & $\begin{array}{l}-1.680 \\
(-1.792)\end{array}$ & $\begin{array}{c}-0.749 \\
(-0.483)\end{array}$ & $\begin{array}{c}-4.330 \\
(-1.871)\end{array}$ \\
\hline
\end{tabular}


Table 4 - Comparison of forecast performance on French panel data set

\begin{tabular}{|c|c|c|c|c|c|c|c|c|}
\hline \multirow[b]{2}{*}{ Ranking } & \multicolumn{2}{|l|}{ 1st year } & \multicolumn{2}{|l|}{$5^{\text {th }}$ year } & \multicolumn{2}{|l|}{$10^{\text {th }}$ year } & \multicolumn{2}{|l|}{ 10-year average } \\
\hline & Estimator & RMSE & Estimator & RMSE & Estimator & RMSE & & RMSE \\
\hline 1. & GLS & 1.818 & Within-2SLS & 4.432 & Within-2SLS & 5.252 & Within-2SLS & 4.107 \\
\hline 2. & Within & 1.836 & Within & 4.545 & Within & 5.568 & Within & 4.223 \\
\hline 3. & Emp. It. Bayes & 1.841 & GLS & 4.568 & GLS & 5.682 & GLS & 4.246 \\
\hline 4. & OLS & 1.880 & OLS & 5.593 & FDGMM & 7.216 & FDGMM & 5.561 \\
\hline 5. & Within-2SLS & 1.885 & FDGMM & 6.061 & FD2SLS & 8.523 & FD2SLS & 5.927 \\
\hline 6. & FD2SLS & 2.124 & FD2SLS & 6.077 & FD2SLS-KR & 8.961 & OLS & 6.097 \\
\hline 7. & FD2SLS-KR & 2.189 & FD2SLS-KR & 6.318 & 2SLS & 9.164 & FD2SLS-KR & 6.190 \\
\hline 8. & It. Bayes & 2.241 & 2SLS & 7.891 & OLS & 10.682 & 2SLS & 7.392 \\
\hline 9. & Emp. It. Bayes IV & 2.291 & 2SLS-KR & 9.702 & 2SLS-KR & 11.240 & 2SLS-KR & 9.147 \\
\hline 10 & FDGMM & 2.469 & GMM & 10.377 & GMM & 12.133 & GMM & 10.058 \\
\hline 11. & Max. Likelihood & 2.566 & Emp. It. Bayes & 12.081 & Average OLS & 14.291 & Emp. It. Bayes & 10.955 \\
\hline 12. & Emp. Bayes & 2.686 & It. Bayes & 12.913 & Emp. It. Bayes & 14.554 & It. Bayes & 11.896 \\
\hline 13. & Max. Likelihood IV & 2.798 & Average OLS & 13.014 & Swamy & 14.571 & Average OLS & 12.690 \\
\hline 14. & It. Bayes IV & 2.812 & Swamy & 13.620 & It. Bayes & 16.359 & Max. Likelihood & 13.258 \\
\hline 15. & Emp. Bayes IV & 2.981 & Max. Likelihood & 13.965 & Average 2SLS & 16.664 & Swamy & 13.264 \\
\hline 16. & Indiv. OLS & 3.283 & Average 2SLS & 14.654 & Max. Likelihood & 19.883 & Average 2SLS & 14.284 \\
\hline 17. & 2SLS & 3.410 & Emp. It. Bayes IV & 15.425 & Emp. It. Bayes IV & 22.822 & Emp. It. Bayes IV & 15.014 \\
\hline 18. & Indiv. 2SLS & 3.797 & Emp. Bayes & 16.274 & Emp. Bayes & 23.392 & Emp. Bayes & 15.731 \\
\hline 19. & 2SLS-KR & 4.574 & Max. Likelihood IV & 19.982 & Max. Likelihood IV & 35.495 & Max. Likelihood IV & 20.883 \\
\hline 20. & GMM & 5.821 & Emp. Bayes IV & 20.654 & Emp. Bayes IV & 38.439 & Emp. Bayes IV & 21.949 \\
\hline 21. & Average OLS & 9.198 & It. Bayes IV & 22.196 & It. Bayes IV & 47.598 & It. Bayes IV & 24.896 \\
\hline 22. & Average 2SLS & 9.738 & Indiv. OLS & 23.254 & Indiv. OLS & 60.922 & Indiv. OLS & 28.367 \\
\hline 23. & Swamy & 9.909 & Indiv. 2SLS & 24.070 & Indiv. 2SLS & 66.610 & Indiv. 2SLS & 30.035 \\
\hline
\end{tabular}

RMSE $\times 10^{-2}$ 
Figure 1 - Distribution of the long run income per capita elasticities among the 21 French regions over 1975-1998

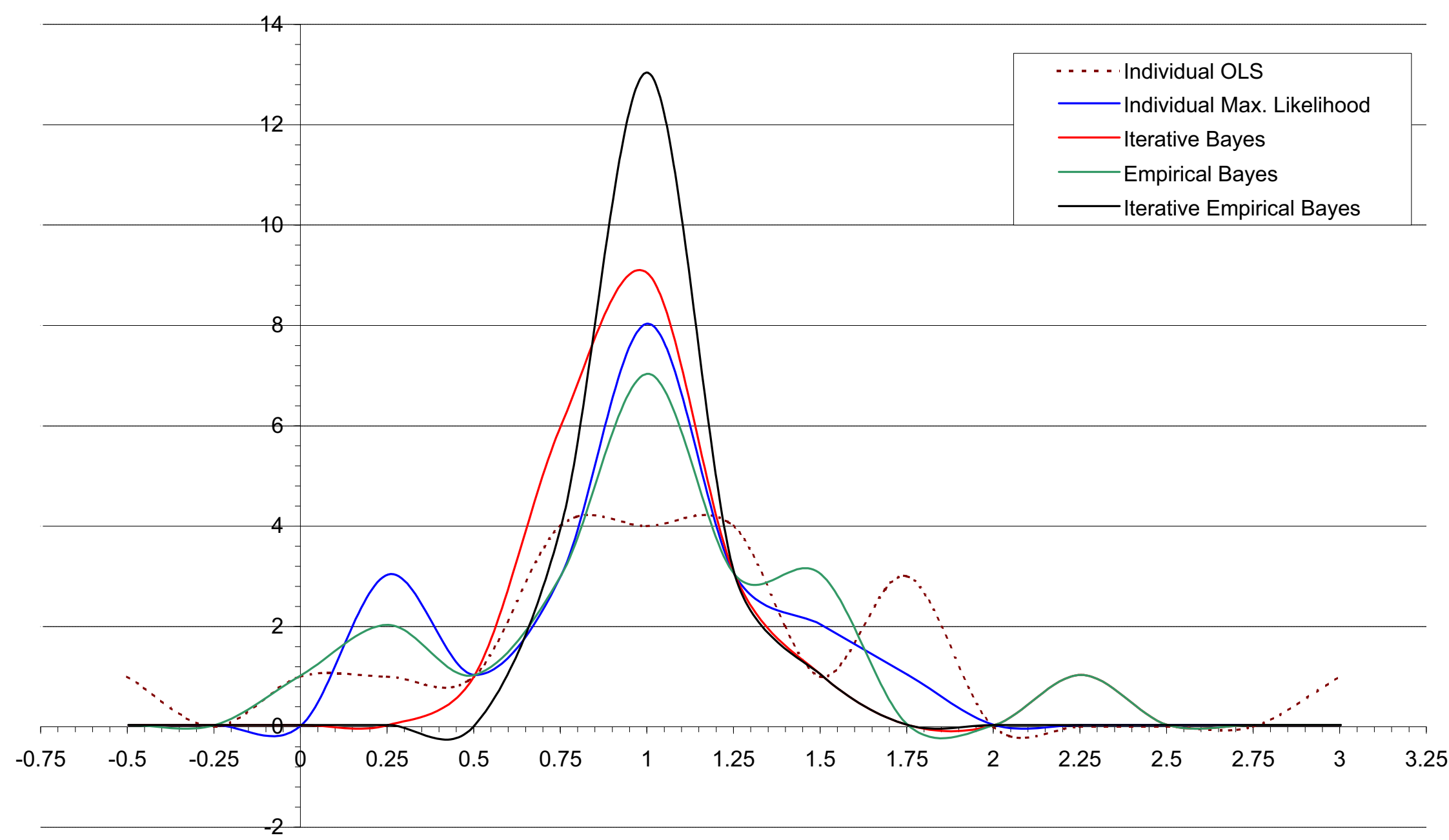

Heterogeneous and shrinkage estimators 

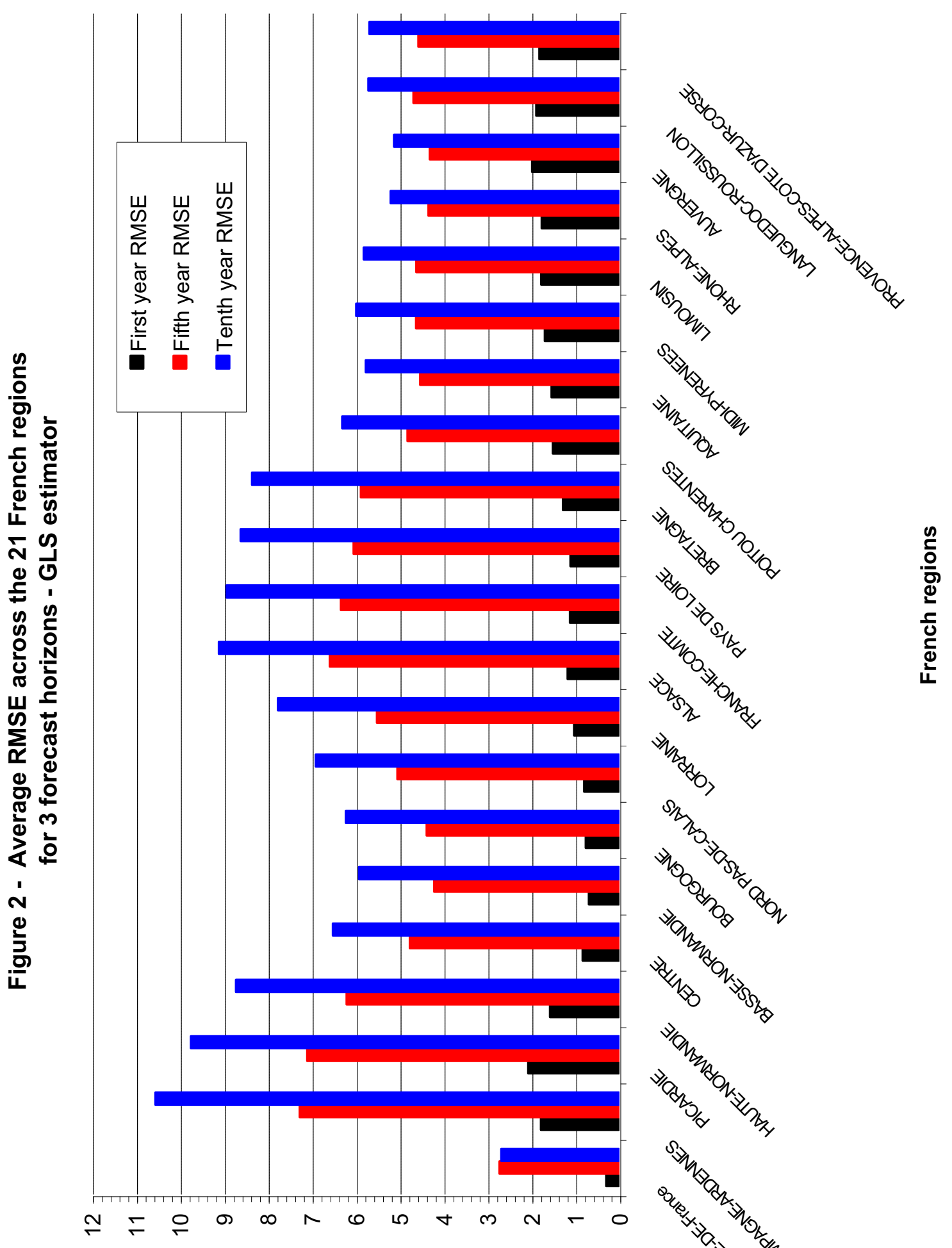

z-0l X ヨSwy 